von den Arzneiwirkungen, sie sind mit dem gegenwärtigen Zustand der Materia medica unvereinbar.

10) Die Sitte, metallische Präparate, namentlich"Antimonizm in die Sarsaparill-Abkochungen einzuhängen, stammt von unwissenden und gewinnsüchtigen Quacksalbern;氵ilure Nützlichkeit ist nicht gehörig nachgewiesen.

11) In der Armenpraxis und in Hospitälem verdient die Wurzel der Smilax aspera als Surrogat der amerikanischen Sarsaparill eingeführt zu werden.

12) Die Herren Hancock, Naumann, Batka, Beral u. s. w. haben sich wesentliche Verdienste um die richtigere Kenntniss dieses wichtigen Arzneimittels erworben.

\title{
Ueber das sicilische Opium;
}

\author{
von \\ Prestandrea, \\ Apotheker zu Messina.
}

Die Herren Savarese und Tenore haben schon gezeigt, dass das Opium, welches in der Gegend von Neapel gewonnen wird, dem thebaischen gleich ist.

Ich liess ein Instrument von Stahl verfertigen mit drei Klingen, die ohngefähr drei Linien von einander entfernt standen, und maclue am Morgen damit Finschnitte in die Mohnköpfe. Der daraus hervorquillende Milchsaft verdickte sich bald nach Mittag. Jeden Tag wurden die Einschnitte wiederholt, bis die Oberfiäche der Kapseln damit ganz bedeckt war. Diese Einschnitte müssen nur die Epidermis und eben die fleischige Substanz treffen, weil man sonst auch die Faser verletzt und der Milchsaft auch in das Innere der Kapsel fliesst. Nach sechs Tagen war diese Arbeit beendet, 
nachdem man jeden Tag Morgens zwei und Abends eine Stunde darauf rerwendet hatte. Obgleich man im Allgemeinen empfohlen hat, die Einschnitte des Abends zu machen, und am folgenden Morgen das Opium zu sammlen, so verfuhrich doch aus dem Grunde nicht so, weil die am Morgen fallende Feuchtigkeit einen Theil des Opiums auflöst, am Stengel herunterfliesst und einen nahmhaften Verlust verursacht. Der viröse Geruch, welchen die eingeschnittenen Kapseln ausgeben, ist so stark, dass ich von einem heftigen Kopfweh und grosser Abspannung ïberfallen wurde. Der verdickte Milchsaft wurde der Sonne ausgesetzt und hatte nach acht Tagen ganz das Anseln des thebaischen Opiums, auch verhielt er sich nach den Versuchen, die mehre geschickle Aerzte damit anstellten, in therapeutischer Hinsicht eben so. Eine Unze dieses Opiums gab 28 bis 3o Gran Morphium, also fast eben so viel wie das thebaische. Dieses Resultat möge die Bewohner Siciliens veranlassen, diese Cultur zu adoptiren, denn unbeschadet dieses wichtigen Produkts erhält man von den Samen nachher noch ein gutes Tafelöl.

\section{Aufbewahrung der Canthariden;}

$$
\text { Lucian Piette. }
$$

Die lebenden Canthariden giebt man in ein irdenes Gefäss mil weiter Oeffnung, und giesst dann, je nach der Ménge der Thierchen, etwas Lavendel-oder Rosmarinöl, oder das ätherische Oel sonst einer Labiate darauf. Die Thierchen sterben bald, man lässt sie in der Wärme oder an der Sonne trocknen. Sie behalten ihre schöne grüne Farbe, einen angenehmen Geruch und man kann sie mehre Jahre aufbewahren, ohne dass sie von Milben angegriffen werden. 